Research Article

\title{
Design optimization of Process Parameters for TIG Welding based on Taguchi Method
}

\author{
Nirmalendhu Choudhury $^{\dot{A}}$, Ramesh Rudrapati ${ }^{\dot{\mathrm{A}^{*}}}$ and Asish Bandyopadhyay ${ }^{\dot{A}}$ \\ ${ }^{\dot{A}}$ Mechanical Engineering Department, Jadavpur University, Kolkata - 700032, India.
}

Accepted 11 January 2014, Available online 01 February 2014, Special Issue-2, (February 2014)

\begin{abstract}
The present study pertains to the improvement of ultimate load of stainless steel - mild steel weld specimen made of tungsten inert gas $(T I G)$ welding. $L_{16}$ orthogonal array $(O A)$ of Taguchi method has been used to conduct the experiments using several levels of current, gas flow rate and filler rod diameter. Statistical techniques analysis of variance (ANOVA), signal-to-noise ( $S / N)$ ratio and graphical main effect plots have been used to study the effects of welding parameters on ultimate load of weld specimen. Optimum parametric condition obtained by Taguchi method. Confirmatory test has been conducted to validate the predicted setting
\end{abstract}

Keywords: Tungsten Inert gas Welding, Taguchi Method, Ultimate Load, Analysis of Variance, Signal-to-Noise Ratio, Optimum Parametric Condition.

\section{Introduction}

Tungsten inert gas (TIG) welding is an arc welding process that produces coalescence of metals by heating them with an arc between a non-consumable electrode and the base metal (Kumar and Sundarrajan, 2009). TIG welding offers several advantages i.e. joining of dissimilar metals, low heat affected zone, absence of slag etc. In TIG welding operation, weld quality mainly depends on features of bead geometry, mechanical-metallurgical characteristics of the weld and various aspects of weld chemistry. These features are greatly influenced by the welding parameters such includes current, voltage, gas flow rate, electrode stick-out, edge preparation, position of welding, weld speed (Ghosh et al 2013) etc. Selection of filler rod material also has significant effect on weld quality. Selection of optimum parametric setting is essential for obtaining desired weld quality. Literature shows that work has been explored on different aspects of modeling, simulation and process optimization in TIG welding.

Tarng and Yang (1998) used Taguchi application to analyze the significance of process parameters on weld bead geometry. Experiments have been planned as per orthogonal array of Taguchi method. Optimal parametric condition was obtained by Taguchi method. Again Datta et al (2008) applied Taguchi philosophy for obtaining optimal parametric combinations to achieve desired weld geometry and dimensions related to the heat affected zone in submerged arc welding. Esme et al. (2009) had done investigation on TIG welding process for an optimal parametric combination to yield favorable bead geometry

*Corresponding author: Ramesh Rudrapati

DOI: http://dx.doi.org/10.14741/ijcet/spl.2.2014.03 of welded joints. They used grey-Taguchi method application to optimize multi-responses bead width, bead height, penetration, area of penetration, HAZ and tensile load simultaneously. Kumar and Sundarrajan (2009)used Taguchi method to optimize the pulsed TIG welding process parameters of heat-treatable (Al-Mg-Si) aluminum alloy weldments for maximizing the mechanical properties. Another work presented by Zhang et al (2012) optimization of an aluminum profile extrusion process based on signal-to-noise ratio of Taguchi methodology. Anawa ans Olabi (2008) applied $\mathrm{CO}_{2}$ continues laser welding process for joining a dissimilar AISI 316 stainless-steel and AISI 1009 low carbon steel plates. They used Taguchi approach as statistical design of experiment technique for optimizing the selected welding parameters in terms of minimizing the fusion zone and they found satisfactory results. Tarng et al (2011) used neural network to construct the relationship between welding process parameters and weld pool geometry in TIG welding. Patil and Kadam (2013) applied artificial neural fuzzy interface system to maximize weld strength and optimum metal deposition rate in welding of dissimilar metals stainless steel and mild steel. Again Lenin et al (2010) optimized process parameters for maximizing weld strength in manual metal arc welding for joining of dissimilar metal stainless steel and carbon steel. They utilized Taguchi application to analyze the effects of each welding parameter on the weld strength by analysis of variance (ANOVA).

In the present work, it is planned to determine the optimal parametric condition in TIG welding of dissimilar metals mild - stainless steel to yield desired weld quality in terms of ultimate load. Taguchi approach for process 
optimization has been carried out to maximize the ultimate load of weldment. Confirmatory test has been carried out to check predicted result.

\section{Design of experiments (DOE)}

The competition in the market has forced the manufactures to design and develop product / process with minimal cost as well as time. The design of experiment has emerged as an important tool for achieving objectives. DOE is a statistical technique that allows to run minimum number of experiments to optimize process. Major approaches in DOE are: factorial design, Taguchi method and response surface methodology. In the present work, Taguchi method is used to design and analyze the TIG welding process.

\subsection{Taguchi Method}

Taguchi design of experiment provides a simple, efficient and systematic approach for the optimization of manufacturing process / systems to minimize / maximize the output responses with minimum number of experiments. This technique has been proved efficient tool to optimize many manufacturing problems [Rudrapati et al (2011), Dongxia et al (2012) and Pan et al (2005). The traditional experimental design procedures focus on the average product or process performance characteristics. But the Taguchi method concentrates on the effect of variation on the product or process quality characteristics rather than on its averages. Taguchi approach recommends that this can be done by the proper design of parameters. Orthogonal arrays (OA) is a standard design by which simultaneous and independent evaluation of two or more parameters for their ability to affect the variability of a process characteristic / output response can be done in a minimum number of tests. Subsequently, decision is made for the optimum combination of these parameters (Shaji and Radhakrishnan, 2003). Three quality characteristics in Taguchi method are shown in below.

Nominal is the best: $\frac{S}{N}=10 \log \frac{\bar{y}}{s_{y}^{2}}$

Lower is the best: $\frac{S}{N}=-10 \log \frac{1}{n}\left(\sum y^{2}\right)$

Higher is the best: $\frac{S}{N}=-10 \log \frac{1}{n}\left(\sum \frac{1}{y^{2}}\right)$

Where, $\bar{y}_{\text {is }}$ the average of observed data, $s_{y}^{2}$ is the variation of $y, n$ is the number of observations, and $y$ is the observed data.

The parameter design phase of the Taguchi method generally includes the following steps:

1. Identify the objective of the experiment

2. Identify the output responses and its measurement systems / instruments

3. Identify the factors that may influence the output response, their levels and possible interactions
4. Select the appropriate orthogonal array (OA)

5. Conduct the test described by the trials in the OA

6. Analysis of the experimental data using the statistical techniques signal-to-noise $(\mathrm{S} / \mathrm{N})$ ratio, analysis of variance (ANOVA) and factor effects to identify the significance of process parameters.

7. And find out the optimum levels of factors

8. Verification of the optimal design parameters through confirmation experiment.

\section{Experimental Details}

The plan has been made and work-piece materials (i.e. mild steel and stainless steel) have been cut into desired dimensions. The setup has been made ready and prepared for doing TIG welding. Now butt joints are made under varied conditions of welding as given $\mathrm{L}_{16}$ orthogonal array of Taguchi method. The selected process parameters and its levels are given in Table 1. Photographic view of the experimental set up is shown in Fig. 1. Mild and stainless steel welded sample is shown in Fig.2. Ultimate load tests are conducted in Universal Testing Machine (UTM). After ultimate load test, failure occurred at mild steel portion (Fig.3). The specifications of the Mild and stainless steel samples and UTM are given below.

Universal Testing Machine:

Make: Instron (model 8801);

Capacity: Maximum 1000KN;

Accuracy: $\pm 0.4 \%$;

Table 1 Input parameters and their levels

\begin{tabular}{|c|c|c|c|c|c|}
\hline \multirow{2}{*}{$\begin{array}{c}\text { Process } \\
\text { parameters }\end{array}$} & \multirow{2}{*}{ Units } & \multicolumn{4}{|c|}{ Levels } \\
\hline & & 1 & 2 & 3 & 4 \\
\hline Current (A) & $\mathrm{A}$ & 90 & 100 & 110 & 120 \\
\hline $\begin{array}{c}\text { Glass flow rate } \\
\text { (B) }\end{array}$ & $1 / \min$ & 12 & 14 & 16 & 18 \\
\hline Filler road $(\mathrm{C})$ & $\mathrm{mm}$ & 1.6 & 2 & 2.5 & 3 \\
\hline
\end{tabular}

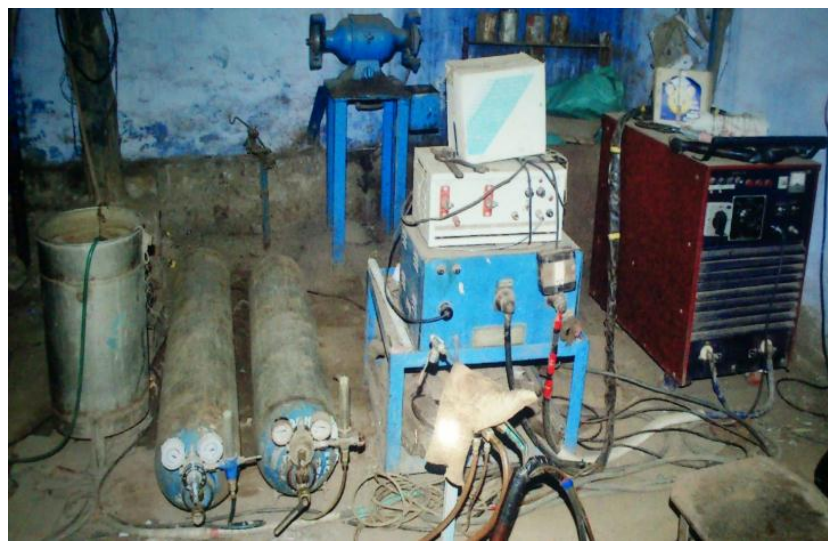

Fig. 1 Experimental setup

Mild steel: length $=85 \mathrm{~mm}$; width $=21 \mathrm{~mm}$; thickness $=$ $3 \mathrm{~mm}$;

Stainless steel: length $=90 \mathrm{~mm}$; width $=25 \mathrm{~mm}$; width $=$ $4 \mathrm{~mm}$;

Working length is $10 \mathrm{~mm}$.. 


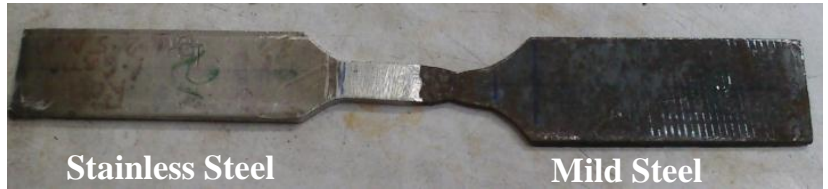

Fig. 2 welded sample

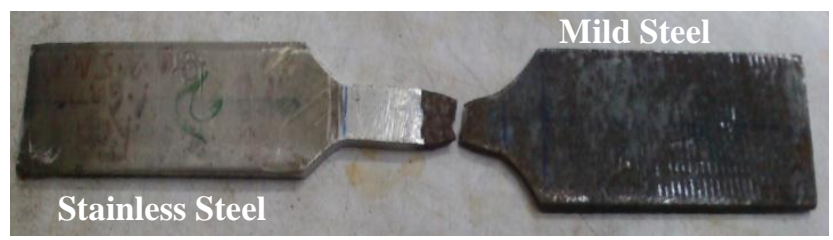

Fig. 3 Failed sample after ultimate load test

\section{Experimental results and discussion}

Experimentation has been completed and ultimate load is measured by conducting the tests on universal tensile machine. Output response is shown in Table 1 , these data is used to further analysis i.e. to determine the optimum welding condition to maximize the ultimate load.

\subsection{Effect of welding parameters}

The statistical techniques analysis of variance and signalto-noise ratio have been applied on observed data to identify the significant input parameters which expected to influence output response (ultimate load). Result of analysis of variance (ANOVA test) is shown in Table 2. In the ANOVA test, F-tests value of the parameters are comparing with the standard $\mathrm{F}$ table value $\left(\mathrm{F}_{0.05}\right)$ at $5 \%$ significance level (95\% confidence level). If P-values in the table are less than 0.05 then the corresponding variables considered as statistically significant. It is found from Table 4 that $\mathrm{P}$ values for current, glass flow rate and filler road are greater than 0.05 . This means that none of these parameters do have significant effect on the ultimate load at $95 \%$ confidence level.

$\mathrm{S} / \mathrm{N}$ ratio of UL is calculated for each parametric combination using Taguchi method and shown in Table 3. On examination of the Delta values, glass flow rate $(B)$ is found to be most significant factor, next is current and followed by filler road. By using these $\mathrm{S} / \mathrm{N}$ ratio values given in Table 3, the main effect plots have been made using MINITAB 16 software and shown in Figure 2. While calculating $\mathrm{S} / \mathrm{N}$ ratios values, larger-the-better criteria have been applied, because ultimate load needs to maximize. So Eq. 3 is used for determining the $\mathrm{S} / \mathrm{N}$ ratios, shown in Table 3 . In a main effect plots, if inclination of the line is more, then the corresponding parameters is more significant parameter and inclination is less, then the effects of the corresponding factor is less. From main effect plots (Figure 4), it is found that current (A) and glass flow rate (B) are considerably significant on ultimate load whereas filler rod (C) has lesser effect. Optimum parametric setting can be found from the main effect plots at highest $\mathrm{S} / \mathrm{N}$ ratio values of UL corresponding to each factor. From Figure 4, it is observed that the optimum condition is $\mathbf{A 2} \mathbf{B 3} \mathbf{C 2}$ (i.e. current $(\mathrm{A})=100 \mathrm{~A}$, glass flow rate $(B)=181 / \mathrm{min}$ and filler $\operatorname{rod}(C)=2 \mathrm{~mm})$.

Table $1 \mathrm{~L}_{16}$ orthogonal array and output response

\begin{tabular}{|l|l|l|l|l|}
\hline S.No. & A & B & C & $\begin{array}{l}\text { Ultimate } \\
\text { Load }\end{array}$ \\
\hline 1 & 90 & 12 & 1.6 & 13.8 \\
\hline 2 & 90 & 14 & 2.0 & 13.7 \\
\hline 3 & 90 & 16 & 2.5 & 12.2 \\
\hline 4 & 90 & 18 & 3.0 & 13.1 \\
\hline 5 & 100 & 12 & 2.0 & 13.9 \\
\hline 6 & 100 & 14 & 1.6 & 12.1 \\
\hline 7 & 100 & 16 & 3.0 & 14.8 \\
\hline 8 & 100 & 18 & 2.5 & 14.5 \\
\hline 9 & 110 & 12 & 2.5 & 12.8 \\
\hline 10 & 110 & 14 & 3.0 & 12.1 \\
\hline 11 & 110 & 16 & 1.6 & 13.9 \\
\hline 12 & 110 & 18 & 2.0 & 13.2 \\
\hline 13 & 120 & 12 & 3.0 & 13.7 \\
\hline 14 & 120 & 14 & 2.5 & 12.8 \\
\hline 15 & 120 & 16 & 2.0 & 13.8 \\
\hline 16 & 120 & 18 & 1.6 & 14.8 \\
\hline
\end{tabular}

Table 2 Analysis of variance for ultimate load

\begin{tabular}{|l|l|l|l|l|l|}
\hline Source & DF & $\begin{array}{l}\text { Seq } \\
\text { SS }\end{array}$ & $\begin{array}{l}\text { Adj } \\
\text { MS }\end{array}$ & F & P \\
\hline A & 3 & 0.82 & 0.27 & 0.72 & 0.57 \\
\hline B & 3 & 1.47 & 0.49 & 1.30 & 0.35 \\
\hline C & 3 & 0.38 & 0.12 & 0.34 & 0.79 \\
\hline Error & 6 & 2.27 & 0.37 & & \\
\hline Total & 15 & 4.97 & & & \\
\hline
\end{tabular}

Table 3 Response table for signal-to-noise ratio of ultimate load

\begin{tabular}{|l|l|l|l|}
\hline Level & $\begin{array}{l}\text { Current( } \\
\text { A) }\end{array}$ & $\begin{array}{l}\text { Gas flow rate } \\
\text { (B) }\end{array}$ & Filler road (C) \\
\hline 1 & 22.40 & 22.63 & 22.68 \\
\hline 2 & 22.79 & 22.05 & 22.70 \\
\hline 3 & 22.27 & 22.70 & 22.31 \\
\hline 4 & 22.77 & 22.85 & 2.54 \\
\hline Delta & 15 & 4.97 & 0.39 \\
\hline Rank & 2 & 1 & 3 \\
\hline
\end{tabular}

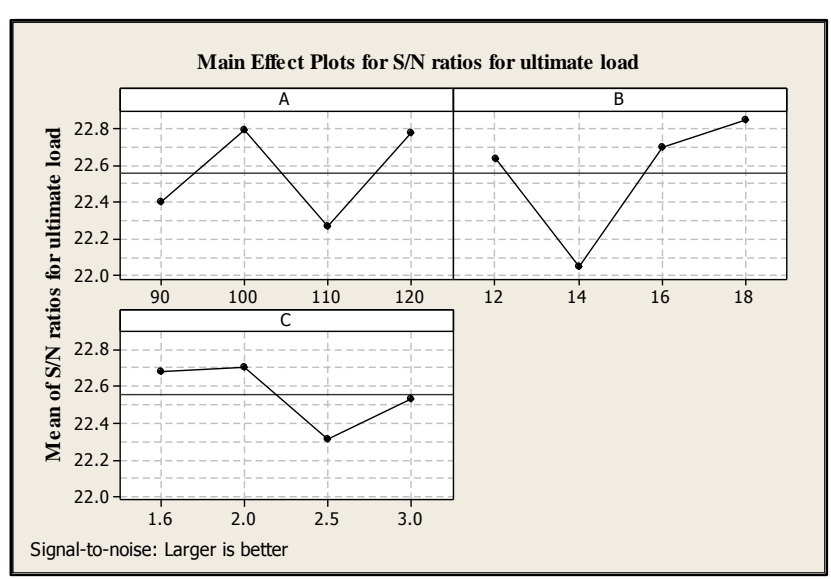

Fig. 4 Main effect plots for ultimate load 
The adequacy of the model has been investigated by the examination of residuals. The difference between the respective observed response and the predicted response is called residuals; those are examined by using normal probability plot and plot of the residuals vs. predicted response. if the model is adequate, the residual points on the normal probability plot should from a straight line. On the other hand the plot of residuals vs. predicted response should be structure less i.e. it should contain no obvious pattern. From the normal probability plot (Fig. 5), it is found that the residuals fall on a straight line; it implies that the errors are distributed normally. The plot of residual vs. predicted / fitted surface roughness values (Fig. 6) reveals there is no obvious pattern and unusual structure. This implies that the proposed model is adequate and there is no reason to suspect any violation of the independence or constant variance assumption (Ashvin and Nanavati (2013), Noordin et al (2004).

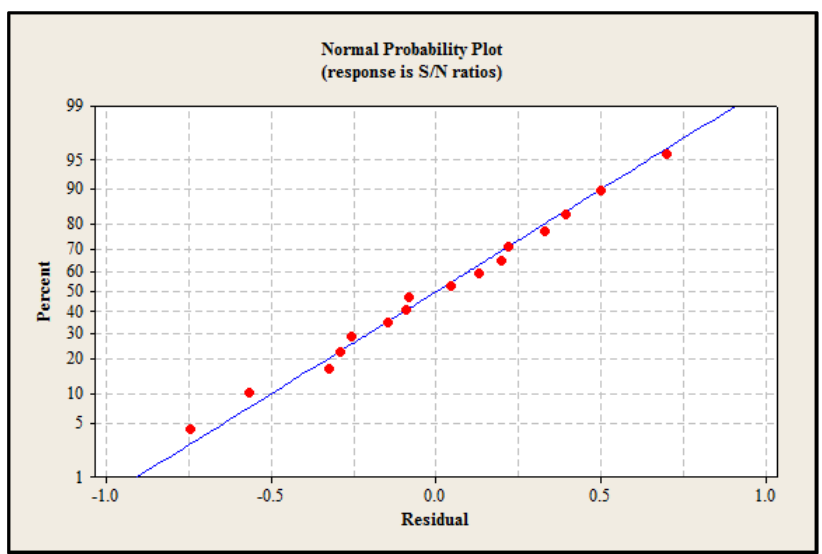

Fig.5 Normal probability plot of residual for ultimate load

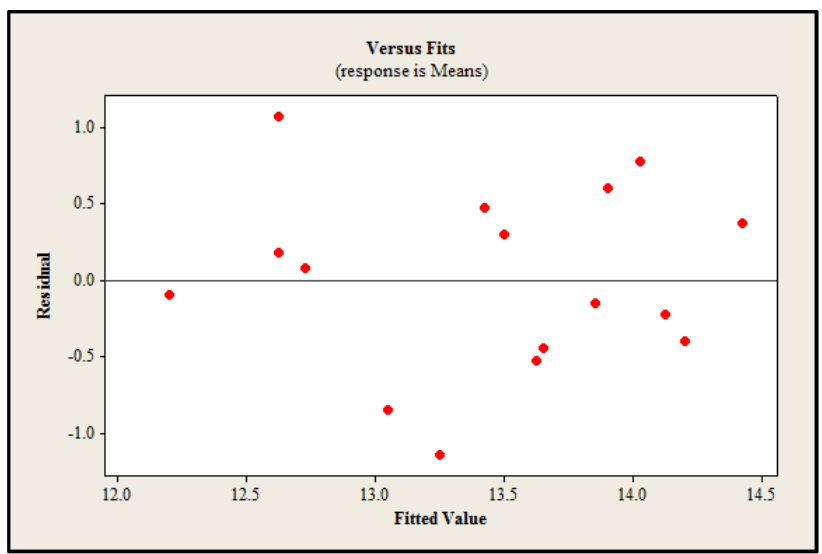

Fig.6 Plot of residual vs. fitted ultimate load values

\section{Confirmatory test}

Confirmatory test is conducted at optimal parameter combination (A2 B3 C2) to check the validity of the optimum welding condition. From the results of confirmatory test, it is found that optimum welding parametric condition produced maximum UL, this value shows the validation of the proposed optimization methodology.
Table 4 confirmatory test results

\begin{tabular}{|l|l|l|}
\hline \multicolumn{2}{|l|}{$\begin{array}{l}\text { Obtained optimum parametric condition } \\
\text { by Taguchi method }\end{array}$} & $\begin{array}{l}\text { Obtained } \\
\text { ultimate load by } \\
\text { confirmatory test }\end{array}$ \\
\hline Current (A) & $100 \mathrm{~A}$ & $\begin{array}{l}\text { Ultimate load = } \\
15.1 \mathrm{MPa}\end{array}$ \\
\hline Glass flow rate (B) & $18 \mathrm{l} / \mathrm{min}$ & \\
\hline Filler road (C) & $2 \mathrm{~mm}$ & \\
\hline
\end{tabular}

\section{Conclusions}

This paper has described the use of Taguchi method and statistical techniques ANOVA and S/N ratio for analyzing and optimizing the ultimate load in TIG welding of stainless steel - mild steel specimens. From the study, the following conclusions are drawn

1. From the ANOVA results, it is found that none of the welding parameter does not effecting the ultimate load.

2. Main effects plots revel that current and gas flow rate are the factors which has considerable influence on ultimate load. Filler rod has small / lesser influence.

3. The optimum welding condition obtained by Taguchi method is: current $=100 \mathrm{~A}$, gas flow rate $=18 \mathrm{l} / \mathrm{min}$ and filler $\operatorname{rod}=2 \mathrm{~mm}$.

4. Confirmation test is confirms the improvement of the UL which also indicates the validity of the present optimization procedure by using Taguchi methodology.

\section{References}

A. Kumar and S. Sundarrajan, (2009), optimization of pulsed tig welding process parameters on mechanical properties of aa5456 aluminum alloy weldments, Materials and Design, 30, pp. 1288-1297.

N. Ghosh, Pal, P.K, G. Nandi and R. Rudrapati, (2013), Experimental investigation of TIG welding of austenitic stainless steel with change in composition of filler material", Proceedings of the National Conference on Recent Trends in Manufacturing Science and Technology (RTMTS-2013), pp. 27-35, NITTR Kolkata,

Y.S. Tarng and W.H. Yang, (1998), Optimisation of the weld bead geometry in gas tungsten arc welding by the Taguchi method, International Journal of Advanced Manufacturing Technology, 14, pp. 549-554.

S. Datta, A. Bandyopadhyay. and Pal. P.K, (2008), Application of Taguchi philosophy for parametric optimization of bead geometry and HAZ width in submerged arc welding using mixture of fresh flux and fused flux" International Journal of Advanced Manufacturing Technology, 36, pp. 689-698.

U. Esme, M. Bayramoglu, Y. Kazancoglu and S. Ozgun, (2009), Optimization of weld bead geometry in tig welding process using grey relational analysis and Taguchi method", Materials and Technology, 43, pp. 143-149.

C. Zhang, G. Zhao, H. Chen, Y. Guan and H. Li, (2012), Optimization of an aluminum profile extrusion process based on Taguchi's method with S/N analysis", International Journal of Advanced Manufacturing Technology, 60, pp. 589599.

E.M. Anawa and A.G. Olabi, (2008), Using Taguchi method to optimize welding pool of dissimilar laser-welded components, Optics \& Laser Technology, 40, pp. 379-388. 
M. Yosefieh, M. Shamanian and A. Saatchi, (2011), Optimization of the pulsed current gas tungsten arc welding parameters for corrosion resistance of super duplex stainless steel welds using the Taguchi method", Journal of Alloy and Compounds, 509, pp. 782-788.

U.S. Patil and M.S. Kadam, (2013), Effect of the welding process parameters in MMAW for joining of dissimilar metals and parameter optimization using artificial neural fuzzy interface system, International Journal of Mechanical Engineering and Technology, 4, pp.79-85.

N. Lenin, M. Sivakumar and D. Vigneshkumar, (2010), Process parameter optimization in ARC welding of dissimilar metals, Thammasat International Journal of Science, 15, 1-7.

R. Rudrapati, A. Bandyopadhyay and P.K. Pal, (2011), Investigation on surface roughness in cylindrical grinding, AIP Conference Proceedings, 1315, pp. 1359-1364.

Y. Dongxia, X. Li, D. He, Z. Nie and H. Hui, (2012), optimization of weld bead geometry in laser welding with filler wire process using Taguchi approach, Optics \& Laser Technology, 44, pp. 2020-2025.
L.K. Pan, C.C. Wang, Y.C. Hsiao and K.C. Ho, (2005), Optimization of Nd:YAG laser welding onto magnesium alloy via Taguchi analysis", Optics \& Laser Technology, 37, pp. 3342.

S. Shaji and V. Radhakrishnan, (2003), Analysis of process parameters in surface grinding with graphite as lubricant based on the Taguchi method, Journal of Material Processing Technology, 141, pp. 51-59.

J.M. Ashvin and J.I. Nanavati, (2013), Optimisation of machining parameters for turning operations based on RSM, Measurement, 46, pp. 1521-1529.

M.Y. Noordin, V.C. Venkatesh, S. Sharif., S. Elting and A. Abdullah, (2004), Application of RSM in Describing the Performance of Coated Carbide Tools When Turning AISI 1045 Steel, Journal of Material Processing Technology, 145, pp. $46-58$ 